\title{
Alzheimer's Disease and the Conflict between Ethics, Morality and Politics
} David Alvargonzález*

Department of Philosophy, University of Oviedo, Spain

\begin{abstract}
Numerous ethical problems are known to follow in the wake of Alzheimer's disease (AD). This paper posits that some of these problems may best be discussed by considering both the distinction between ethics, moralities and politics and the conflicts arising from these three spheres of reality. Following Spanish philosopher Gustavo Bueno, an initial distinction is established in which 1) ethical norms and virtues seek to ensure the life of the human individual and the human person; 2) moral norms and virtues seek the smooth running of a given group; and 3) political norms and virtues seek the viability of a political state. The paper then moves on to characterize a specific subset of ethical problems involved in AD; here the distinction between human individual and human person proves to be particularly relevant. It focuses later on the conflict between the ethical universal virtues and moral norms of certain groups, such as families, doctors and certain other cultural groups, by studying their influence on the persons suffering from AD. Finally, the state's role is taken into consideration, since the conflict between ethics and politics arises whenever health care officials try to cut costs at the expense of the heroic sacrifice made by some people. For its part, the conflict between morality and politics emerges when the interests of different groups collide, and whenever policies must be implemented to allocate scarce resources. The paper ends by suggesting that the proposed distinction may help understand some of the pressures acting on both people suffering from $A D$ and on people making decisions about them.
\end{abstract}

Keywords: Ethics; Morality; Politics; Alzheimer's; Personhood; Compassion; Quality of life; Euthanasia; Dignity; Disclosure

\section{Introduction}

Rather than presenting the results of scientific or medical research on Alzheimer's disease (AD), this paper raises an abstract, philosophical discussion. Philosophy is not a positive science; this, however, does not mean that philosophical theories are mere opinions, since they entail a certain, abstract sui generis structuring and organization of phenomena. The paper first presents the advantages of dissociating three different domains of reality (ethics, morality and politics), and the stakes involved in analyzing the relationships and conflicts between them. It then moves on to discuss the way AD can be viewed from each of these domains while showing how ethical, moral and political values and norms may come into conflict in the process of making decisions to address this dreaded disease.

\section{Ethics, Morality and Politics}

As a starting point, I will present the distinction between ethics, morality and politics following the theories of the materialist philosopher Gustavo Bueno [1,2]. At first appearance, the discussion on the differences between these three terms might seem a matter of the lexical meanings of certain words and their usage in modern languages such as English, Spanish, French, Italian and others. Digging further, I will argue that the distinction between ethics, morality and politics is not only an issue of words but is in fact the very foundation upon which three different domains of reality are based. For my purposes, the debate on which words we choose to refer to each of these three areas of reality (ethics, morality, politics) is another matter altogether, as my interest lies not in discussing words but in discussing the realities designated by those words. Additionally, I do not intend that the distinction and characterization of these three areas of reality take the appearance of a stipulation, although this may be unavoidable in an initial brief summary such as this. The only remedy to such a criticism is provided by the utility the distinction has, in analyzing specific issues, a utility which shows the distinction to be not purely speculative or lexical, but as befitting the structure of certain relevant phenomena.
My position is that the distinction between ethics, morality and politics lies in the supposition that human persons, as they go about their daily lives, are required to face certain purposes, each of a different nature. The first purpose is to preserve the integrity of each human subject, as both a biological individual and a human person. Gustavo Bueno relates such a perspective to ethical norms and virtues. Following Spinoza, "strength of character" stands as the fundamental ethical virtue (incidentally, the Greek root "ethos" means "character"); this is understood as "firmness" when applied to oneself and as "generosity" when applied to others [3]. Aiming to transform ill patients into healthy individuals and thereby contribute to restoring their firmness, the sound practice of medicine is an inherently ethical activity guided by the virtue of generosity. Unethical behaviors, on the contrary, threaten personal integrity and the biological individual, and include murder, mutilation, abuse, torture, defamation, injury and any other behavior geared toward undermining another person's strength. Equally unethical is any behavior which works against one's own self, such as drug abuse, careless eating and health habits and suicide. Basic assumptions dictate that biological and personal integrity must be respected and enhanced regardless of sex, age, religion, ethnicity, language, etc. With this in mind, ethical norms strive to be universal and distributive, since they are fully distributed in every human individual. Ethical norms may come into conflict with each other, as occurs when the prohibition against killing may be overridden in cases of self-defense. In such cases, the ethical rule to defend one's own

*Corresponding author: David Alvargonzález, Department of Philosophy, University of Oviedo, C. Teniente Alfonso Martínez, SN, 33071, Oviedo Spain, Tel: 34 985104356, 34 649010040; Fax: 34 985104385; E-mail: dalvar@uniovi.es, davidalvargonzalez@gmail.com

Received January 08, 2013; Accepted March 10, 2013; Published March 20 2013

Citation: Alvargonzález D (2013) Alzheimer's Disease and the Conflict between Ethics, Morality and Politics. J Alzheimers Dis Parkinsonism S10: 004. doi:10.4172/2161-0460.S10-004

Copyright: (c) 2013 Alvargonzález D. This is an open-access article distributed under the terms of the Creative Commons Attribution License, which permits unrestricted use, distribution, and reproduction in any medium, provided the original author and source are credited. 
life clashes with the rule to protect the life of another. This is resolved through the assumption that the defender's firmness should prevail over the attacker's life.

A second, different set of purposes faced in human daily praxis is the preservation and the smooth maintenance of certain groups of humans. These may be a family, brotherhood, sect, religious confession, trade association, gang of drug traffickers or terrorists, secret society, mafia, guild, social class, political party, an age-based or sex-based group or any number of other groups. All people, by virtue of their family, social background, gender, language, profession, age, education, religious beliefs and the like, inevitably belong to certain groups possessing a wide variety of interests and particular customs. Each group has its own mores and its own internal rules based on these mores, thus enabling its preservation and progress. Taking cues from Gustavo Bueno, I refer to those norms as "morality". This usage is evident in expressions such as "Victorian morality", "Christian morality", "bourgeois morality" or in Nietszche's analysis of "master and slave morality". Victorian bourgeoisie, Christians and masters and slaves are groups of people with different interests. As Bueno points out, loyalty to and solidarity with other group members are the cardinal moral virtues. The famous proverb "there is honor among thieves" serves as an illustration of a typical moral motto.

In many cases ethical rules and virtues do not enter into conflict with the morality of a given group, but sometimes they do. Objectively, such a conflict seems unavoidable at certain times. The prohibition for Jehovah's Witnesses to receive blood transfusions may lead to a person's death in the face of the most elementary ethical requirements. Political loyalty may push party members into conflict with the ethical duty to avoid perjury and defamation; the members of a professional association (doctors, politicians, judges) may unethically protect one another, and thus their group, from external attacks. It must be stressed that moral norms are designed to safeguard the group, even if it is necessary to sacrifice the lives or interests of any of its members (to say nothing of outsiders). Additionally, the moral rules of one group may clash with those of another, since moral norms are not necessarily shared by different groups. Occasionally the conflict even affects one single person belonging to two different groups, such as when internal solidarity with a family group may clash with the professional duties of some of its members as policemen, judges or teachers. In other cases conflicts are due to confrontation between two groups with incompatible interests and moralities: Christians and the Taliban, militarists and pacifists, etc.

Other rules which inevitably influence human practices are referred to as political norms. While the word "politics" has been used in a wide sense, I will give it a more restricted meaning and refer to everything contributing to the smooth running of an existing state [4]. In this restricted sense, political norms are explicitly sanctioned by the state's legal order. As with moral norms, many political norms peacefully coexist with ethical norms and even enhance ethical virtues, but on certain occasions, political and ethical norms collide. Ethical norms demand helping all the needy people throughout the world and receiving them all to improve their living conditions. However, if the government of a given state were to take this ethical ideal as a policy requirement, it would jeopardize the viability of the state and the welfare of its citizens. Boundaries, coastguards, fences, policing, confinements and deportation are painful but necessary measures for the smooth running of the state. As such, any state has to suspend the universality of ethical rights and content itself with the more modest goal of rendering these rights possible within its borders.

Recognizing the incompatibility between ethical and political norms has been one of academic philosophy's classical issues from the beginning. In the Apology and Phaedo, Plato relates the story of Socrates's death. Socrates is the wisest, most virtuous and most fair of all humans Plato had ever met and yet he represents, for the polis's democratic government, a threat to the smooth running of the city, and so he must die. Socrates's friends offer him the chance to flee to escape this wrongful conviction, but Socrates decides to stay and face the fate Athenian democracy has reserved him. Yet another illustration of the conflict between ethical and political norms is that of soldiers who must kill to defend their country. An individual who claims the right to refuse military service can ground this conscientious objection on ethical arguments about the wickedness of murdering other people. In spite of the abstract validity of his/her grounds, such a refusal turns out to be a betrayal of the country; in wartime, no such legal precedent may be establish, since a state lacking a suitable army is a state at the mercy of its enemies. Somebody must do this ethically dirty work. Accordingly, policies and political rules should sometimes be "beyond (ethical) good and evil", and not only in degenerated, violence-prone tyrannies but also in modern parliamentary democracies. In all cases, this is the cost of the smooth running of the state. Equally conflictive is the relationship between political and moral rules. A healthy state requires tireless combat against organized crime; the need for an army to defend the nation-state disallows the growth of pacifist groups above a certain level. Furthermore, the political norms of different states may also be incompatible. It was, after all, the Nazi political ideal of a unified Europe under the Aryan race which led to the World War II. The examples could continue, but space constraints limit further illustrations of the objective conflict between ethics, morality and politics.

Ethical norms, insofar as they affect every human person regardless of his/her status, should be understood as universal. Moral and political norms, however, insofar as they arise from certain groups and states, are subject to the dialectics of cultural relativism [5]. Consequently, moral rules and policies divide humanity into different groups which confront one another in the same way as languages and religions do. However, the fact that ethical norms are universal does not mean that they dwell beyond the political sphere. The (ethical) right to personal integrity or the right to enjoy adequate health care would be worthless if there were no state capable of enforcing that right within a particular legal order via judges, police and the army. Citizens in the US, Canada and myriad other countries enjoy these rights not as "human beings" or "citizens of the world" but as citizens of a particular state. If that person were a citizen of another state he/she might not enjoy these rights. Therefore, civic engagement in that particular state and civic engagement to further that state's viability is necessary to make ethical rules and rights possible. Any claim to serve solely universal ethics "beyond political good and evil" proves chimerically idealistic.

\section{Some Ethical Problems Related to AD}

The discussion on certain ethical issues raised by $\mathrm{AD}$ requires reference to the classical distinction between the human individual and the human person. In this paper, I will follow the idea of human person as defended by Bueno [6] and Hughes $[7,8]$. The idea of human individual is primarily constructed from a biological, zoological perspective. We speak of human individuals as we do about individuals of any other species. Individuals are born, grow, feed, reproduce and, ultimately, die. Death is a process common to human and non-human individuals, and even to organisms other than animals. Conversely, the idea of human person is of a specifically anthropological character. In this paper, I assume that human beings alone can be persons in the strict sense; there are no such things as incorporeal persons such as angels or 
spirits. Against supporters of the Great Ape Project, I further claim that non-human animals, such as chimpanzees, gorillas and orangutans, are not persons when living in the wild [9]. Finally, I maintain that a "legal person" (a company, a corporation) is a persona ficta, a fictitious person, and that the concept of "legal personality" is the result of a catachresis.

The human individual progressively becomes a person through his/ her interaction with the other members of the "society of persons". This surrounding society decisively contributes to the constitution of the new person from the outside. The process of learning a particular language and the process of internalizing the customs of a given society play a cardinal role in the constitution of a new human person. Thus, human persons are not self-constituted or genetically preformed but develop from both within and as shaped from without. The idea of personhood as a cultural and social construct has been widely defended [8,10-22].

The distinction between human individual and human person is at play in many modern languages which differentiate between the verbs "to die" and "to pass away". Death, the transformation of a living organism into a cadaver, is preferentially reserved for individuals, whether human or non-human animals. Human persons pass away as personhood gradually fades concurrently with the deterioration and disappearance of relationships with other persons.

In the most frequent, canonical situation, one biological human individual corresponds to one human person, but there are some exceptions to this case, such as parapagus conjoined twins, where two human persons are confined in a single human individual. In previous work, I have distinguished up to eight different cases of dissociation between the human individual and the human person [23]. Such a distinction proves useful when trying to understand the consequences of $\mathrm{AD}$. As is well known, the afflicted persons suffer a progressive destruction of brain structure and as result they lose a significant portion of their ability to interact with others. The histological degenerative processes experienced by $\mathrm{AD}$ sufferers severely affect their competence as human persons, especially once the disorganization stage has begun.

Any discussion of this depersonalizing process strongly requires an explicit epistemological stance. Kitwood [24], in various influential works on $\mathrm{AD}$, has over-emphasized the role malignant social psychology plays as both trigger and aggravator of brain degeneration in afflicted persons. Kitwood cites treachery, disempowerment, intimidation, labeling, stigmatization, outpacing, invalidation, banishment and objectification as some of the methods consciously or unconsciously used by the hostile environment surrounding the person with $\mathrm{AD}$ [14]. While I do recognize the role these circumstances play in accelerating the depersonalization process, it seems to me that Kitwood disregards the important role that the physiological etiology of neuronal damage has at both the start and in the course of the disease. It seems evident that the ongoing physiological degeneration due to $\mathrm{AD}$ progression is the main cause of depersonalization. Contrary to the most extreme socio-psychological interpretation, $\mathrm{AD}$ is not just a behavioral disorder, such as an anxiety disorder. As Adams has shown, Kitwood has not yet proven the causal relation between life events and brain failure in dementia [24]. Unfortunately, Alzheimer's disease is much more than a mere social construction [25]: Post, in The Moral Challenge of Alzheimer's Disease, is much more realistic about the true and despairing face of this illness, especially at its end stage [17].

As mentioned above, AD implies a progressive loss of mental abilities leading to the deterioration of the personal relationships in all areas of life. AD poses special philosophical problems, since the progressive brain damage and corollary depersonalization of the afflicted is irreversible even when provided the most person-centered care. The firmness of the sick person is compromised from the moment he/she begins to lose the ability to care for him/her in the most basic aspects of daily life. To compensate, this lack of firmness must be filled from outside by the generosity of the surrounding people. As stated above, personhood implies the existence of human individuals endowed with healthy human brains interacting one with another. As such, as the brain of the afflicted person deteriorates, the accompanying depersonalization must be compensated from the outside by the enhancive personalizing process of those surrounding such a fading personhood. Such is the ethical ideal of the virtue of generosity and the ethical challenge of this devastating illness. Consequently, the Spinozistic ethics herein adopted view all the depersonalizing behaviors listed by Kitwood as unethical, since they assume a lack of generosity and a direct attack against the sufferer's remaining personhood and firmness [14].

This distinction between human individual and human person has sometimes been used to argue that AD sufferers eventually, after a gradual depersonalization process, reach a moment in which their lives are no longer worth living. I staunchly reject this on the grounds that personhood is not an all-or-nothing matter. Memory and abstract reasoning measured by standardized tests are hardly the sole criterion to evaluate personhood. As Sabat has pointed out, severely afflicted persons may still have the capacity to experience shame, embarrassment and pride, may still be concerned to maintain dignity and may still retain the capacity to worry for the wellbeing of others [20]. Those struggling to maintain their identity should not be underestimated; Kontos has also convincingly claimed that "despite the loss of memory, the body itself still possesses a life force that continues to engage with the world" [26]. While an AD sufferer's behavior may seem uncoordinated and pathetic, it must nevertheless be interpreted in its human, personal context [7]. Personhood may be highly deteriorated and fragmented but it does not disappear completely. Ethical behavior requires sustaining this remaining personhood until the end.

As such, the assisted suicide of people suffering from $\mathrm{AD}$ cannot be based on ethical norms and virtues. From the standpoint of Spinoza's Ethics, suicide does not imply strength of character but, on the contrary, must be understood as a lack of firmness, since firmness implies selfpreservation [27]. The reasons for both sick and healthy individuals to commit suicide may be numerous, but it seems contradictory to endorse these reasons as ethical. As widely recognized, a person suffering late-stage $\mathrm{AD}$ lacks the necessary firmness to commit a planned and conscious suicide (accidental death is another situation altogether) Another person who practices homicide on request is needed, which itself leads to an irresolvable ethical problem since, as mentioned above, ethical virtues require sustaining the remaining personhood and prevent the killing of another person. As in other cases of attempted suicide, ethical behavior aims not at encouraging suicide but at aiding the afflicted to regain his/her lost firmness [23].

\section{$\mathrm{AD}$ and the Conflicts between Ethics and Moralities}

People with $\mathrm{AD}$ and people coexisting or attending $\mathrm{AD}$ sufferers (relatives, friends, doctors, caregivers) belong to myriad different groups. Each of these groups faces unique problems and has to struggle to see that it runs smoothly and remains viable. If a given group implements rules by compromising its own survival, then one of two things can happen: either the group rectifies those rules, or the group itself disappears. In the previous section I have shown that ethical virtues are aimed at promoting the firmness of the sick person by 
suitable treatment for the biological individual (according to the state of scientific medicine) and at strengthening the firmness and personhood of the sufferer by providing proper treatment and preventing the malignant psycho-sociology referenced by Kitwood [14]. This ethical behavior is frequently compatible with the moral rules of the groups touched by the disease, but there are other times when ethical virtues and moral requirements take divergent and even conflicting paths. The following deals with two important groups involved in $\mathrm{AD}$, the family and the doctors, and their attitude on euthanasia. In the end I will analyze a situation concerning diagnostic disclosure where ethical fundamentalism may be counterproductive.

\section{$\mathrm{AD}$, euthanasia and the viability of the family}

Families caring for a relative with $\mathrm{AD}$ experience immense stress arising from the many emotional and physical challenges and demands placed on family members. In terms of financial, social and emotional cost, $\mathrm{AD}$ is more disruptive to the family than other diseases [28]. Disagreements as to the level of impairment, differences of opinion regarding medical treatment or care facilities and differences in understanding the caregiver's role are a frequent source of family conflicts. Furthermore, stark contrasts often exist in the level of care provided by one family member with respect to the others, as one family member assumes the burden of caring while the others avoid the afflicted relative, and this imbalance can also lead to conflict. Changing relationships may also be another source of open or hidden conflict, as family members look to rewrite their relationships with each other and with the person with $\mathrm{AD}$. In all these cases, the relative's health will continue to deteriorate in spite of the best care. This produces feelings of guilt, frustration and discouragement. Moreover, violence in both patients and caregivers is not unusual: " $15.8 \%$ of patients had been violent in the year following diagnosis and a total of $5.4 \%$ of caregivers reported being violent toward the patient" [29]. Even further, family conflict may induce depression in the primary caregiver and anger in the family toward the person with AD [30]. Family conflict continues to have important implications for caregivers who have their relatives admitted to institutions [31]

The burden of some terminally-ill persons may even be considered too heavy for the family to bear. The ethnographic record provides telling examples of the way certain cultures face this problem. Although they are not specifically related to $\mathrm{AD}$, these anthropological illustrations, in my opinion, provide relevant contextual cues for the discussion of some current problems, as I will show. Described in many pre-Hispanic cultures of South and Central America are certain anthropological institutions enabling euthanasia for the elderly who suffer from incurable, terminal diseases. A minimum list of peoples with such practices includes: the Guaycuru people of the Gran Chaco region in Argentina, Bolivia, Paraguay and Brazil; the indigenous Cueva of the Darién region in eastern Panama; the Huichol or Wixáritari of the Sierra Madre range in western central Mexico; the Bororo Indians of the Mato Grosso region in central Brazil; the Puelches of the Puelmapu region in the eastern Andes; the Fuegians of Tierra del Fuego at the southern tip of South America; and the Tucuman Indians in northwestern Argentina. On many occasions a shaman dispenses the euthanasia, but on others the task is reserved for close friends or relatives. In many places in Hispanic America, the person who "removes the suffering" of the terminally-ill elderly person through an easeful killing is called the despenador. In Argentina, the physician and philosopher Giuseppe Ingegnieri claimed that, in certain circumstances, the task of despenar (literally meaning "to remove suffering" but actually meaning "to kill") was seen as a friend's duty even as late as the early $20^{\text {th }}$ century. The failure to deliver this euthanasia was considered dishonorable and cowardly. Particularly noteworthy is Ingegnieri's appeal to the duties of friendship and honor, which I have taken to be values of a moral nature. The tribe decides to promote euthanasia after carefully considering and discussing both the dangers of living with a terminal illness and the need to be gone with it. Natives often think that the hopelessly ill elderly members carry evil spirits, and the proposed euthanasia is the institutionalized way of getting rid of them. Along the same lines and based on the aforementioned ethical-moral distinction, the universal timeless war practice of killing off badly wounded enemies is not the result of a compassionate concern, but rather the moral recognition that the proper execution of war does not allow for their care.

The existentialist writer and ethics adviser Baroness Mary Warnock has argued that elderly people suffering from dementia should consider ending their lives because they are a burden on their families. Claiming that their duty is to die for the sake of their loved ones, she declares, "If you're demented, you're wasting people's lives -your family's livesand you are wasting the resources of the National Health Service" [32]. In her view, this sense of moral duty is acting in the afflicted person without any external coercion:

"It is argued, however, that to request death and receive assistance to die from a sense of duty is not something to be abhorred. It may be a genuinely desired good death for someone who has lived his life, partly at least, seeking the interest of others [33]".

"(The person suffering dementia) may hate to see (their relatives) sucked into her suffering, their own lives disrupted and torn apart by the need to care for her, or pay for someone else to do so. This patient genuinely cannot bear to see the damage to the life of her family, whom she has always hitherto looked after and protected as far as possible from harm. The reversal of roles may be something she genuinely wants to bring to an end, and therefore she wants death. After all, up to this point, a person will be admired if he really wanted to do his duty, or what he regarded as in the best interests of his family, his colleagues, his community or his country. He will be thought well off for not always preferring his own interests to those of others [33]".

Such circumstances throw into question the priority that the virtue of firmness takes over the virtue of generosity. Given the inevitable end of the disease, the afflicted person resolves to perform a final act of generosity for his/her relatives by releasing them from having to suffer unnecessary burdens. Thus, the sick person's ethical virtue of firmness is sacrificed to the service of the family; in other words, it is put to use as a moral norm commensurate to heroes sacrificing themselves to save the group. However, if the afflicted were to attempt suicide while still being autonomous, his/her family and friends would have to oppose that suicide on the grounds of the ethical virtue of generosity. This is the general process followed in ordinary cases of attempted suicide, when family members, friends, psychologists and other professionals do their best to persuade the suicide-prone to give up from their deathseeking intentions. If the sick person, guided by this internalized moral requirement, leaves some instructions in advance directing other people (friends, physicians, relatives) to kill him/herself at due time, then the conflict arises whereby those people thus requested must refuse to follow such directives if they are to obey the ethical virtue of generosity. From the tenets of this paper, a person killing the demented person does so not in an act of generosity but in an act of firmness, which seeks the best for the group. This is what is sought by the afflicted person when requesting the easeful death (his/her finis operantis) and is also the objective end goal (finis operis) pursued in such an act. In this case, the conflict between ethics and morality works out in favor of morality, 
in favor of the group. For its part, the executor of euthanasia displays the virtue of loyalty, as seen in the Argentinean despenadores described above by Ingegnieri. This, though, is what I have argued to be a moral virtue, which here frontally opposes the ethical norm against killing.

In their influential 1979 book, Beauchamp and Childress defined four basic ethical principles: beneficence, non-maleficence, autonomy and justice [34]. By their account, these four principles should be weighed one against the other when applied to individual cases. Gradually, a defense of the person's autonomy in making his/her own decisions concerning personal matters has been gaining support in the face of paternalistic healthcare ideology. Warnock and MacDonald have done just that in their defense of autonomy to enforce compliance with the person's decision to receive euthanasia [35]. Although generally an indicator of health, autonomy may obviously be exercised by people to commit to decisions contrary to ethics. For instance, the autonomous decision to commit suicide cannot be considered an ethical decision when evaluated from the Spinozistic ethical standpoint I have taken as a touchstone. Freedom and autonomy are necessary but not sufficient conditions for ethical action. While terminally-ill people tend to view themselves as a burden on the family [36], our external encouragement and exacerbation of such a negative view only perpetuates unethical action by further eroding the sufferer's firmness. Ethics implies and requires combating pain, depression and feelings of hopelessness, despair and abandonment and giving attentive, person-centered care. In this context, appealing to the principle of autonomy may mask the indirect and subtle group pressure acting on the persons suffering the disease, which leads them to request their own "voluntary" euthanasia. The objective conflict between ethical and moral norms is hereby relegated to the "autonomous" decision-making process of the terminally-ill person, right at the time when their position is most vulnerable and their firmness most fragile.

The ideas of honor and dignity in dying have also been used to encourage requested assisted suicide. Employed by the "Dying in Dignity Society" in Great Britain or the "Association for the Right to Die with Dignity" in Belgium, these ideas are driven by certain confused imperatives regarding aesthetic standards and by psychological circumstances relative to analgesia. Nevertheless, these unwritten values about dignity are unethical the moment they encourage preventive suicide, however indirectly. While the death scene may be terrible from an aesthetic or interoceptive standpoint, the death itself should not be classified as humiliating or dishonorable: Jesus's death, the death of a drowned captain who had saved others from shipwreck, and the violent and painful death of warriors on the battlefield serve as just a few illustrations. The difference between the death of AD sufferers by natural causes and their death by euthanasia does not hinge on that the former is "dishonorable" while the latter is a "death with honor", for dying with dignity and honor chiefly depends on the treatment survivors provide to the moriturus $[37,38]$.

\section{AD, euthanasia and the Hippocratic Oath}

Another area of conflict between ethical and moral norms may arise from the relationship between the people suffering from $\mathrm{AD}$ and their doctors. The Hippocratic Oath can be understood either as an ethical or a moral norm. Ethically, it is but an individual case of the ethical virtues and norms specified above. In the previous section I have assumed this interpretation by taking the medical profession to be intrinsically ethical. Kass has defended and analyzed this idea in depth [39]. For purposes of argument, though, suppose the Hippocratic Oath were mainly a moral norm for the guild of physicians. From this perspective, the refusal of physicians to practice active euthanasia may be understood as the rule of a group refusing to assume a task they consider to be outside their practice, in the same way as doctors consider the euthanizing execution of those sentenced to the death penalty to be outside their professional practice. Barnard Baumrin has argued that doctors must not engage in assisted suicide because in doing so they are eroding the public trust doctors inspire; he goes on to say that prestige of the profession could be adversely affected by such a practice [40]. Pellegrino has also supported this argument [41]. As it stands, even the precepts of the "compassionate concern" argument do not logically require physicians qua tale to be particularly committed to the requirement of assisted suicide.

Continuing in the interpretation of the Hippocratic Oath as a moral norm, the claim advocating that physicians administer euthanasia to $\mathrm{AD}$ sufferers under certain conditions could be understood as the interest to put the administration of certain practices in the hands of corporate medicine instead of in the hands of other groups. Rachels [42] explicitly advocates for this extension of the field of medicine:

"We can define a different profession, very much like medicine, but called (perhaps) 'smedicine'. Smedicine, as we shall define it, is the profession which does everything it can to treat illness, cure disease, and repair the human body, so long as there is any point to it; but, when the possibility of a meaningful life is gone, smedicine helps make the passage to death as easy as possible. We could argue that medicine, which (we are assuming) precludes this latter kind of help, is morally defective, and should be abandoned, to be replaced by the better practice of smedicine [42]".

Following this argument, Gary Seay defends physician-assisted suicide since "physicians have special duties toward those who cannot be cured" and, consequently, "the conception of medicine as essentially devoted to healing the sick and preserving and extending life (...) is incomplete" [43]. Whatever the case may be, while the abstract, individual and ethical perspective condemns the practice of assisted suicide, moral perspectives may lead to different assessments of what is best for the medical profession. As illustrated, some of these proposals may be incompatible with ethical ideals.

\section{$\mathrm{AD}$ and diagnostic disclosure}

Disclosing diagnostic information to patients with $\mathrm{AD}$ and their families poses some important problems. According to Kitwood, when physicians diagnose a person with $\mathrm{AD}$, the person is discredited as a "demented person". This "labeling" contributes to a malignant atmosphere and may generate expectations of progressive decline $[14,15]$. While disclosing the diagnosis may contribute to externally induced depersonalization and may cause damage to the public image of the person suffering from $\mathrm{AD}$, many professionals have also pointed to the advantages of early diagnosis in reducing anxiety and the emotional burden to the afflicted people and their families [44] The difficulty is further compounded by the new guidelines for $\mathrm{AD}$ of the National Institute of aging and the Alzheimer Association [45-48] A diagnostic expansion to suppose preclinic stages of $\mathrm{AD}$ include the mild cognitive impairment (MCI) and even some other asymptomatic and controversial early stages supposedly detected by biomarkers, imaging technologies, or genetic testing $[49,50]$.

Cultural idiosyncrasy regarding the administration of information and decision-making concerning dreaded diseases complicate things even further. In the US, certain groups, such as Mexican Americans, Korean Americans and the Navajo, place information and decisions concerning health and death more frequently in the hands of family members than in those of the sick person. In Ireland, 83\% of relatives 
of people with dementia are against disclosing the diagnosis to the patient [51]. In playing a protective role, this family authority can be understood as part of a collective decision-making process. Acting from a collective moral authority, the family may withhold relevant information whenever divulging it would harm the sick person by producing anxiety, stress and/or depression. Whenever the afflicted expects such a handling of information on his/her illness, disclosure could prove counter-therapeutic and may produce a nocebo effect. Under such circumstances, the ethical requirement of veracity and full diagnostic disclosure, taken as an inviolable ethical norm, may be harmful to the firmness of the sick person [52]. As Beauchamp and Childress have judiciously argued in their classical treatise on medical ethics, a person's autonomy implies a right to choose and a right to be informed, but not a mandatory duty to choose or to receive unwanted information [34].

It is worth noting that acknowledging this dialectic between ethics and morality does not necessarily imply a relativistic standpoint with respect to bioethics, such as that proposed by Megan-Jane Johnston [52]. Bioethics, she claims, is a culture-bounded discourse because its principles are none other than those of the group morality of Western white people and doctors [52]. My view, though, sees Spinozistic ethical virtues as universal and distributive, touching every human person and being independent of cultural idiosyncrasy [5]. In an abstract, ideal, ethical situation, the person suffering from a disease should be able to know his/her diagnosis because concealing this information could be understood as a kind of disqualification undertaken by doctors or/and relatives. However, as mentioned above, personhood is not an individual somatic feature but an external construction effectuated within the "society of persons". Consequently, the firmness of a given person depends largely on the people around him/her, and these people belong to a particular culture. Some groups, such as the close family, may under certain circumstances contribute decisively to maintaining the personhood and firmness of the terminally-ill person. In their "terror management theory", Greenberg et al. have stated that cultural worldviews can be of significant help in managing feelings of vulnerability, helplessness and insignificance and can work as safeguards against death anxiety. This "therapeutic effect" of being "inside" certain shared collective beliefs can raise the self-esteem of persons facing death, and one of such collective beliefs is the unwritten norm of hiding a bad diagnosis [53]. In such circumstances, the rote enforcement of the abstract, ideal, ethical norm of diagnostic disclosure implies a deculturation of the terminally-ill person and can prove catastrophic "because it undermines the cultural mechanisms that otherwise enable people to assuage their death-related anxieties and maintain belief in their significance, dignity, and worth as human beings in the cosmos" [52]. From this standpoint, informed consent can, in certain circumstances, be seen as a "violation of the protective role and collective decision-making authority of the family" [52].

When universal ethical norms enter into conflict with the moral norms of a culture or a family group, the adoption of a fundamentalist, ethical approach which violates, thwarts or "sets back" the morality of the afflicted person may produce a boomerang effect since questioning the beliefs of a sick person who is in a condition of extreme fragility may eventually be detrimental and may erode his/her remaining firmness.

Understanding this dialectic between universal ethics and a particular morality may help physicians seeking a prudential balance in their decisions concerning diagnostic disclosure by taking into consideration the cultural values of the people involved. Some additional monitoring also seems necessary to ensure that the collective decisions made by the family are not detrimental to the sick person. At any rate, as Johnston has stated, much more research is needed in this area because " $(. .$.$) cultural differences in end-of-life care remain$ poorly understood, poorly guided and poorly resourced in the health care sector $(\ldots) "$ " [52]

\section{The Politics of AD}

$\mathrm{AD}$ has become a major public health issue due to its high incidence, its increasing prevalence, the long duration of illness, the high cost of care and the absence of effective therapies. According to the 2012 estimates by the Alzheimer Association of the United States, prevalence in the US (number of cases at a given time) is around 5.4 million Americans and will reach 7.7 million in 2030. Incidence (number of new cases in a given time period) is growing as baby boomers age: as of 2010, 450,000 new cases were diagnosed and 615,000 new cases a year are expected in 2030. The Association calculates that patients survive between four and eight years after diagnosis, with $40 \%$ of this time spent in the most severe stages. The average cost per person of Medicare benefits for people with $\mathrm{AD}$ is $\$ 43,847$, while the average cost for people with other pathologies is $\$ 13,879$. Aggregate payments for people with $\mathrm{AD}$ (health care, long-term care and hospice) for 2012 hover around $\$ 200$ billion and are estimated to increase up to $\$ 1.1$ trillion in 2050 (in 2012 dollars) [54]. As is well known, there are no effective therapies, and symptomatic treatments must be re-adjusted and re-evaluated throughout the course of illness. Furthermore, people with $\mathrm{AD}$ are more likely to have other chronic diseases (diabetes, coronary heart disease, congestive heart failure, etc.).

Contrary to Roberston, I assume that $\mathrm{AD}$, as a diagnostic category, is not merely a social or political construction [25]. I will also contend that population aging is an issue relevant to the political agenda when projecting estimates about the increasing prevalence and incidence of AD. Discussing whether this trend could be labeled as "apocalyptic" (as Roberston critically does) is not my priority. While agreeing with the difficulties revealed by Bloom et al. in estimating the costs of the disease, I will end by asserting the evident importance of the disease's national costs and the indubitability of the progressive growth of those costs due to increased incidence [55]. Finance ministries and insurance companies, as expected, face this growing demand for services with concern.

\section{The conflict between politics and ethics}

Every time AD patients become very ill, every time their care grows burdensome, difficult and expensive, every time effective therapies remain out of reach, every time the persons' health progressively worsens in an inevitable march towards death and every time any effort to personalize the sufferer from the outside is cut off by the progression of the disease, ethics norms and values stand to lose. With this in mind, Stoic ethics help establish a framework in which these norms and values should be understood. In his fourth Meditation, Marcus Aurelius states, "The universe is change; life is firmness" (" $\delta$ kó $\sigma \mu \varsigma$

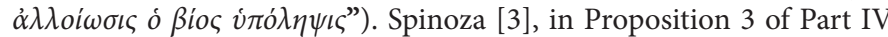
of his Ethics, provides further insight, reminding us that "the force whereby a man persists in existing is limited, and is infinitely surpassed by the power of external causes". According to this Stoic ethics, Post has judiciously argued against the technocratic protraction of morbidity in the advanced stage of AD [17]. Against Ann Roberston's [25] assertions, the tragedy of Alzheimer's disease should not lead us to deny it and assume it to be a merely social or political construct. Anyway, social, psychological and physiological factors could be thought together instead of opposed [56]. Unfortunately, the disease does have a 
physiological basis, and the progressive aging of Western societies (the change of population graphics from pyramid to coffin) plays a key role in its increasing incidence [54]. Similarly, I oppose Megan-Jane Johnston in her belief that avoiding certain metaphors when referring to $\mathrm{AD}$ can conjure away the dreadful nature of this illness [57]. In point of fact, the person with $\mathrm{AD}$ suffers a progressive loss of personal control. The disease robs and steals much of his/her previous personality; it is an enemy to be combated. Although it is not a contagious disease, its increasing prevalence and incidence can be seen as a social tragedy possessing something of "epidemic" character. AD intrinsically carries great personal drama and, unfortunately, in order to face it, the ethical virtues of firmness and generosity cannot prevail. The struggle must be faced under the aegis of Stoic philosophy.

$\mathrm{AD}$ is inevitably accompanied by a disheartening prognosis on the ultimate course of illness. There is nothing alarmist, apocalyptic or purely metaphoric in this affirmation [54,57,58]. Furthermore, from the point of view of public health agents, the cost of caring for people suffering from $\mathrm{AD}$ is significantly higher than the cost of care for other diseases. Under these circumstances, the temptation to subtly promote beneficent requested euthanasia should not be underestimated [25]. As it has been suggested, advance directives and advance care planning may be part of a strategy designed to limit costly treatments for terminally-ill patients once they lose the ability to speak on their own behalf $[41,58,59]$. In varying forms, laws enabling euthanasia have been already passed in the Netherlands, Belgium, Switzerland and in the American states of Oregon and Washington. Without reserve, Mary Warnock has held that demented people have a duty to die because they are a burden on the state and waste NHS resources [32].

In this setting, Megan-Jane Johnstone has identified an ideology playing an important role in this requested euthanasia [57]. As mentioned, $\mathrm{AD}$ implies a progressive loss of personal control. To face this hopeless process, the ideas of self-determination and autonomy, as illustrated in the motto "My life, my death, my choice", encourage the ill person to make the helpless, heroic decision to request assisted suicide. Such a request acts as a final revolt against the disease, as if this lost control could be regained. This, of course, is merely illusion, for euthanasia is neither a treatment nor a remedy. As Johnstone has stated, euthanasia is not the control over life and death (we have little or no control over such matters) but rather is an ultimate act of submission [57]. Only if research develops effective therapy in the future will control over the disease cease to be illusory. I agree with Megan-Jane Johnstone in the ideological use of the metaphor whereby the ill person represents him/herself as a cornered soldier who prefers suicide to being captured by the enemy [52]. However, the person with $\mathrm{AD}$ is not responsible for his/her illness and there is no honor in struggling against biological causes. Once again, a certain degree of Stoicism seems advisable.

\section{Politics and the conflict between different groups}

One of the chief functions which political states have performed since their inception is mediating conflicts arising between different groups of people inside the state. The sick may be defined against the healthy (as care recipients and caregivers, for instance). Divisions may extend even further, as interests and needs are not uniform among the sick. As such, people suffering from different pathologies may also come into conflict.

Political decisions may be implicitly stated in general laws or may glimmer through the implementation of budgets. With respect to general laws, in Europe the obligation for families to provide care to the people suffering from $\mathrm{AD}$ differs widely from country to country.
In Spain and Portugal, caring for a dependent family member is an obligation for first-degree relatives, while in the Netherlands, Sweden, Finland, Norway and Denmark family members have few obligations. Conversely, the extent of implemented state support is low in the former group while in the latter the state has explicit statutory obligations to vulnerable people and contributes with higher support [60]. With respect to the way budgets are implemented, state resources are always scarce and, given a certain percentage of GDP to meet health expenses, the problem of setting spending priorities will always persist. Competition between different groups for health resources is "a war of all against all". In this confrontation, the construction of "the elderly" as a category contributes to fuelling intergenerational inequity arguments [25,61]. Detractors of increasing elderly health costs go so far as to posit the existence of a "provider-induced demand" for this care, which is creating an "aging enterprise" [61].

Different groups use different arguments based on their interests and purposes. From the standpoint of strict medical utility, proposals place those for whom no treatment will be efficacious at the bottom of the priorities list. Age discrimination then arises from applying standards of medical utility alongside calculations on the life expectancy of patients. Persons labeled as incurably demented may also suffer discrimination. Longley and Warner find that "there is (in Europe) a discernible general lack of priority given to the needs of those with neurodegenerative diseases" [62]. Accordingly, those who most stand to lose are those people with AD. Even so, researchers argue that the money invested in research can significantly improve the situation of patients and can lead to budgetary savings in the medium term. Khachaturian has calculated that "an initiative aimed at mobilizing the necessary resources to delay the onset of the disease by 5 years for all age groups over 65 years would reduce nearly half the total number of individuals with the disease" [63]. In other words, money invested in research may yield more than that invested in social care. In comparisons of public costs to life expectancy, terminally-ill persons once again end up disadvantaged, since the general consensus in the medical profession favors limiting certain lifesaving procedures or interventions for terminally-ill patients.

Common to all these economic calculations of healthcare policy is the complete depersonalization of patients. Individual persons are numbered into members of groups and these groups are then characterized by measurable variables, if possible (age, costs, times, efficacy, etc.). From an ethical standpoint, though, every individual patient is a person traversing a difficult and vulnerable situation, and every person deserves support to reinforce his/her weakened firmness. Complicating things further, access to public health services is determined by factors such as place of residence, ethnic background, level of culture, nature of illness, prognosis, age and insurance coverage. According to certain theories, political justice is supposed to counteract the inequality of opportunities caused by a misfortune over which the sick person does not have significant control [64]. In all cases, healthcare officials do not take into consideration the ethical virtues of the afflicted people (need, effort, merit, contribution to society) in order to set priorities in part because these ethical issues cannot be quantified.

The "hyper-economic" management of healthcare is at work when using the concept of "quality of life". In certain industries, it is common to distinguish between the quantity and quality of the goods produced. Sociologists and economists have gone a step further and applied this distinction to human issues, thereby ranking countries and cities by their "quality of life" as based on certain indicators, such as the number of swimming pools or theatres. When applied to people, the concept of "quality of life" permits sorting persons into classes, as 
if they were products subject to certain minimum standards of quality. As such, if their "quality of life" deteriorates below a certain minimum level, some "experts" determine that it is not worth expending scarce medical resources on them. By this procedure, the euthanasia of a person labeled as depersonalized, and whose life has thus been declared of minimal value, is depicted as a charitable act. Once the person enters into this compassionate surrounding atmosphere, appealing to patient's autonomy and to patient judgments about quality of life seems problematic. At any rate, if the sicker and more costly ill persons disappear of his/her own accord, public health officials consequently achieve their "quality of life" targets for the population as a whole. As Blank has pointed out, in a general context of scarcity and struggle, advocating preventive euthanasia and advance directives may display a fundamental, resource allocation dimension [65]. To end this discussion on "quality of life", it is worth noting that even people seeking to improve the situation of those suffering from $\mathrm{AD}$ may fall into the trap of talking about "quality of life" and of proposing instruments to measure such a "quality of life" [66,67].

Among forms of government, parliamentary democracies are not always equitable when sharing public health resources, and sometimes they give rise to inconsistent, incomprehensive systems. Due to national, regional and local implementation of healthcare and support policy, interstate inequities are very acute in Europe and also exist in the US [68]. As practiced in a parliamentary democracy, a public health official appointed by a political party may be asked to arrange the allocation of healthcare expenses in such a way as to maximize the number of voters in the next elections. Thus played between different groups, this political game may lead to an unequal and democraticallysanctioned distribution of health services. Conversely, beneficent dictatorships might guarantee the universal right to a minimum level of decent healthcare.

What is certain is that societies differ one from another: some have institutionalized preferential female infanticide while others have not, some encourage sex discrimination while others fight against it, and some have despenadores, executors by euthanasia, to kill their demented elderly citizens while others try by all means to care for them as human persons to the end of their days. It is up to us to decide the kind of society we want to live in and to fight to see that society come to pass.

\section{Epilogue}

At the beginning of this paper, I introduced the distinction between ethics, moralities and politics and pointed out that, at first appearance, it could seem a purely arbitrary and merely stipulative distinction. By now, I hope this early impression has been rectified. Beyond a mere matter of words, it is important to recognize the differences between these three spheres of reality. For people facing a diagnosis of AD, I have shown how they are caught in the crossfire of competing norms, values and interests. On one hand, they have their own interest to survive as well as the ethical norm that they be treated honorably as human persons until the end of their lives; they are the victims of a terrible disease, are in a vulnerable position and have done nothing for which they should feel guilty. On the other hand are the norms and values of those surrounding them: their families, friends, caregivers, doctors, cultural groups, even political parties and, ultimately, the states as lawgivers and providers of healthcare resources. By distinguishing the universal ethical norms protecting human persons from the particular norms benefiting some specific groups (families, professionals, corporations, etc.) and from political state goals, these conflicts of values and interests may be seen in a more clarifying light. In those conflicts "everyone has his/her own burdens to bear". Persons suffering from AD will always bear the worst. Although the task of dissociating ethics, moralities and politics may seem merely theoretical, it may provide some practical help in order to clarify the different and sometimes conflicting values, norms and interests for all involved.

\section{Acknowledgments}

I wish to thank Professor Videnovic for giving me the opportunity to contribute to this special issue of the Journal of Alzheimer's Disease and Parkinsonism. The two reviewers of the Journal made helpful and insightful comments to the firs version of this paper. I also wish to thank Brendan Burke for his help in improving the English and the style of the text. Finally, I want to honor Gustavo Bueno, whose philosophy is the main source of inspiration of this work.

\section{References}

1. Bueno G (1996) Ética y moral y derecho. In El sentido de la vida. Pentalfa, Oviedo: $15-88$

2. Bueno G (2003) En nombre de la ética. El Catoblepas 16: 2.

3. Spinoza B (1677) Ethics. $3^{\text {rd }}$ part, prop. 59

4. Waal F de (2000) Chimpanzee politics. Power and sex among apes. JHU Press, Baltimore.

5. Alvargonzález D (2002) On cultural relativism and some other forms of relativism. Biblioteca nódulo online.

6. Bueno G (1996) Individuo y persona. In El sentido de la vida. Pentalfa, Oviedo: 115-237.

7. Hughes JC (2001) Views of the person with dementia. J Med Ethics 27: 86-91.

8. Hughes JC (2011) Thinking through dementia. Oxford University Press, Oxford: 29-57.

9. Singer $P$, Cavalieri $P(1994)$ The great ape project: Equality beyond humanity. Fourth State Publishing, London.

10. Fortes M (1987) Religion, morality and the person. Cambridge University Press, Cambridge.

11. Harré R (1995) The necessity of personhood as embodied being. Theory \& psychology 5: 369-373.

12. Harre R (1998) The singular self: An introduction to the psychology of personhood. Sage Publications, London.

13. Herskovitz E (1995) Struggling over subjectivity: debates about the 'self' and Alzheimer's disease. Medical anthropology quarterly 9: 146-164.

14. Kitwood T (1990) The dialectics of dementia: With particular reference to Alzheimer's disease. Ageing and society 10: 177-196.

15. Kitwood T (1997) Dementia reconsidered: The person comes first. Open University Press, Buckingham and Philadelphia.

16. Luborsky MR (1994) The cultural adversity of physical disability: Erosion of full adult personhood. J Aging Stud 8: 239-253.

17. Post SG (2000) The moral challenge of Alzheimer's disease. The John Hopkins University Press, Baltimore and London.

18. Sabat SR (2001) The experience of Alzheimer's disease: Life through a tangled veil. Blackwell Publishers, Oxford UK.

19. Sabat SR (2004) Managing psychosocial aspects of Alzheimer's disease. Directions in psychiatry 24: 59-67.

20. Sabat SR (2005) Capacity for decision-making in Alzheimer's disease: selfhood, positioning and semiotic persons. Australian and New Zealand journal of psychiatry 39: 1030-1035

21. Sabat SR, Harré R (1992) The construction and deconstruction of self in Alzheimer's disease. Ageing and society 12: 443-461.

22. Scheibe K (1984) Memory, identity, history and the understanding of dementia The human science approach pp: 141-159. State University of New York Press, New York.

23. Alvargonzález D (2012) Alzheimer's disease and euthanasia. Journal of aging studies 26: 377-385 
Citation: Alvargonzález D (2013) Alzheimer's Disease and the Conflict between Ethics, Morality and Politics. J Alzheimers Dis Parkinsonism S10: 004. doi:10.4172/2161-0460.S10-004

Page 9 of 9

24. Adams T (1996) Kitwood's approach to dementia and dementia care: A critical but appreciative review. J Adv Nurs 23: 948-983.

25. Roberston A (1990) The politics of Alzheimer's disease: A case study in apocalyptic demography. International journal of health services 20: 429-42.

26. Kontos P (2003) The painterly hand: Embodied consciousness and Alzheimer's disease. J Aging Stud 17: 151-170.

27. Spinoza B (1677) The ethics. $4^{\text {th }}$ part, prop. 18

28. Gwyther LP (1998) Social issues of the Alzheimer's patient and family. Am J Med 104: 17S-21S.

29. Paveza GJ, Cohen D, Eisdorfer C, Freels S, Semla T, et al. (1992) Severe family violence and Alzheimer's disease: Prevalence and risk factors. Gerontologist 32: $493-497$

30. Semple SJ (1992) Conflict in Alzheimer's caregiving families: Its dimensions and consequences. Gerontologist 32: 648-655.

31. Gaugler JR, Zarit SH, Pearlin LI (1999) Caregiving and institutionalization: Perceptions of family conflict and socioemotional support. Int J Aging Hum Dev 49: 1-25.

32. Warnock M (2008) A duty to die? Life and Work.

33. Warnock M (2008) A duty to die? OMSORG 4: 3-4

34. Beauchamp TL, Childress JC (1979) Principles of biomedical ethics. OPO, Oxford

35. Warnock M, MacDonald E (2008) Easeful Death. Is there a case for assisted suicide? Oxford University Press, Oxford.

36. McPherson C, Wilson K, Murray M (2007) Feeling like a burden to others: A systematic review focusing on the end of life. Pall Med 21: 115-128.

37. Tadd $W$, Vanlaere $L(2010)$ Clarifying the concept of human dignity in the care of elderly. A dialogue between empirical and philosophical approaches. Ethical Perspectives 17: 253-281.

38. Austin W, Bergurn V, Dossetor J (2003) Relational ethics. An action ethic as a foundation for health care. In Tschudin $V$ (ed) Approaches to ethics: Nursing beyond boundaries. Elsevier, Edinburg.

39. Kass L (1989) Neither for love nor money: Why doctors must not kill. Public Interest 94: 25-46.

40. Baumrin B (1998) Physician, stay thy hand! In: Rhodes MBK, Silver A (eds.)., Physician assisted suicide: expanding the debate. Routledge, New York pp. 177-81.

41. Pellegrino E (1992) Doctors must not kill. In: Misbin R (ed.)., Euthanasia: The good of the patient, the good of society. University Publishing Group, Frederick Maryland pp 33-34

42. Rachels J (1986) The end of life: Euthanasia and morality. Oxford University Press, Oxford: 121

43. Seay G (2001) Do physicians have an inviolable duty not to kill? J Med philos 26: 75-91.

44. Alzheimer's Association (2011) Alzheimer's Disease. Facts and Figures (includes and special report on early detection and diagnosis). Alzheimer's and dementia 7: 45-53.

45. Jack CR Jr, Albert MS, Knopman DS, McKhann GM, Sperling RA, et al. (2011) Introduction to the recommendations from the National Institute on AgingAlzheimer's Association workgroups on diagnostic guidelines for Alzheimer's disease. Alzheimers Dement 7: 257-262.

46. McKhann GM, Knopman DS, Chertkow H, Hyman BT, Jack CR Jr, et al. (2011) The diagnosis of dementia due to Alzheimer's disease: recommendations from the National Institute on Aging - Alzheimer's Association workgroups on diagnostic guidelines for Alzheimer's disease. Alzheimers Dement 7: 263-269.

47. Albert MS, DeKosky ST, Dickson D, Dubois B, Feldman HH, et al. (2011) The diagnosis of mild cognitive impairment due to Alzheimer's disease: recommendations from the National Institute on Aging - Alzheimer's Association workgroups on diagnostic guidelines for Alzheimer's disease. Alzheimers Dement 7: 270-279.

48. Sperling RA, Paul S Aisen, Laurel A Beckett, David A Bennett, Suzanne Craft, et al. (2011) Toward defining the preclinical stages of Alzheimer's disease Recommendations from the National Institute on Aging-Alzheimer's Association workgroups on diagnostic guidelines for Alzheimer's disease. Alzheimers Dement 7: 280-292.

49. Beard RL, Neary TM (2013) Making sense of nonsense: experiences of mild cognitive impairment. Sociology of health \& illness 35: 130-146.

50. Gaines AD, Whitehouse PJ (2006) Building a mystery: Alzheimer's disease mild cognitive impairment and beyond. Philosophy, psychiatry and psychology 13: $61-74$

51. Maguire CP, Kirby M, Coen R, Davis Coakley, Brian A Lawlor, et al. (1966) Family member's attitudes toward telling the patient with Alzheimer's disease their diagnosis. BMJ 313: 529-30.

52. Johnstone MJ (2012) Bioethics, cultural differences and the problem of mora disagreements in end-of-life care: A terror management theory, Journal of medicine and philosophy 37: 181-200.

53. Greenberg J, Pyszczynski T, Solomon S (1986) The causes and consequences of a need for self-esteem. A terror management theory. In Baumeister RF (ed) Public and Private Self (pp.189-212). Springer-Verlag, New York.

54. Alzheimer's Association (2012) Alzheimer's disease. Facts and figures (includes a special report on people with Alzheimer's disease and other dementias who live alone) Alzheimer's Association, New York, pp-67.

55. Bloom BS, Pouvourville N, Straus WL (2003) Cost of illness of Alzheimer's disease: How useful are current estimates? The gerontologist 43: 158-164.

56. Whitehouse PJ, George D (2007) The myth of Alzheimer's: what you aren't being told about today's most dreaded diagnosis. New York, $1^{\text {st }}$ St. Martin Griffin edn.

57. Johnstone MJ (2011) Metaphors, stigma and the 'Alzheimerization' of the euthanasia debate. Dementia 2: 1-17.

58. Johnstone MJ, Kanitsaki O (2009) Population ageing and the politics of demographic alarmism: implications for the nursing profession. Australian Journal of Advanced Nursing 26: 86-92.

59. Burgess M, Stephenson P, Ratanakul P, Suwonnakote K (1999) End-of-life decisions: Clinical decisions about dying and perspectives on life and death. In: Coward H, Ratanakul P (eds.). A cross-cultural dialogue on healthcare ethics. Wilfred Laurier University Press, Ontario, Canada: 190-206.

60. Miller J, Warman A (1996) Family obligations in Europe. Family Studies Centre London.

61. Bytheway B, Johnson J (2005) An ageing population and apocalyptic demography. Radical Statistics 100: 4-10.

62. Longley M, Warner M (2002) The national policy context across Europe Radcliffe Medical Press, Oxon UK.

63. Khachaturian ZS (2007) A chapter in the development of Alzheimer's disease research: A case study of public policies on the development and funding of research programs. Alzheimers Dement 3: 243-258.

64. Rawls J (1971) A theory of justice. Cambridge MA, Cambridge University Press

65. Blank R (2005) End-of-life decision making: A cross-national study. MIT Press, Cambridge MA 1-12

66. Brod M, Stewart AL, Sands L, Walton P (1999) Conceptualization and measurement of quality of life in dementia: the dementia quality of life instrument (DQoL). Gerontologist 39: 25-35.

67. Bond J (1999) Quality of life for people with dementia: approaches to the challenges of measurement. Aging and society 19: 561-579.

68. Warner M, Furnish S, Longley M, Lawlor B (2002) Alzheimer's disease. Policy and practice across Europe. Radcliffe Medical Press, Oxon UK.

Citation: Alvargonzález D (2013) Alzheimer's Disease and the Conflict between Ethics, Morality and Politics. J Alzheimers Dis Parkinsonism S10: 004. doi:10.4172/2161-0460.S10-004

This article was originally published in a special issue, Neurodegenerative Disorders handled by Editor(s). Dr. Aleksandar Videnovic, Northwestern University, USA, Dr. Ubaldo Armato, University of Verona Medical School, Italy Dr. Jesús Avila, Universidad Autónoma de Madrid, Spain. 